\title{
Precursory pattern of tidal triggering of earthquakes in six regions of China: the possible relation to the crustal heterogeneity
}

\author{
Q. Li and G.-M. Xu \\ Nanjing 210014, China \\ Correspondence to: Q. Li (lqdzjybzx@126.com) \\ Received: 8 April 2012 - Published in Nat. Hazards Earth Syst. Sci. Discuss.: - \\ Revised: 27 August 2013 - Accepted: 28 August 2013 - Published: 18 October 2013
}

Research Center for Earthquake Prediction, Earthquake Administration of Jiangsu Province, No.3 Wei Gang,

\begin{abstract}
We found the possible correlation between the precursory pattern of tidal triggering of earthquakes and the crustal heterogeneities, which is of particular importance to the researchers in earthquake prediction and earthquake hazard prevention. We investigated the connection between the tidal variations and earthquake occurrence in the Liyang, Wunansha, Cangshan, Wenan, Luquan and Yaoan regions of China. Most of the regions show a higher correlation with tidal triggering in several years preceding the large or destructive earthquakes compared to other times, indicating that the tidal triggering may inherently relate to the nucleation of the destructive earthquakes during this time. In addition, the analysis results indicate that the Liyang, Cangshan and Luquan regions, with stronger heterogeneity, show statistically significant effects of tidal triggering preceding the large or destructive earthquakes, while the Wunansha, Wenan and Yaoan regions, with relatively weak heterogeneity, show statistically insignificant effects of it, signifying that the precursory pattern of tidal triggering of earthquakes in these six regions is possibly related to the heterogeneities of the crustal rocks. The above results suggest that when people try to find the potential earthquake hazardous areas or make middle-long-term earthquake forecasting by means of precursory pattern of the tidal triggering, the crustal heterogeneity in these areas has to be taken into consideration for the purpose of increasing the prediction efficiency. If they do not consider the influence of crustal heterogeneity on the tidal triggering of earthquakes, the prediction efficiency might greatly decrease.
\end{abstract}

\section{Introduction}

The fluctuating range of tidal stress is far smaller when contrasted with the seismic stress drop (Kanamori and Anderson, 1975); however, in the majority of circumstances, the regular rate of periodic change in tidal stress far surpasses the expected rate of tectonic stress change (Wilcock, 2001). Thus, a tiny fluctuation in tidal stress has the likelihood of triggering an earthquake when the stress accumulates to a critical condition in the source zone. From this point of view, many scientists around the world have studied the effect of tidal triggering of earthquakes. For instance, Kasahara (2002) studied some evidence that tidal forces influence earthquakes associated with volcanic activity; Huang and Liu (2006) studied some anomalous tide responses of a geoelectric field at the Niijima station before the earthquake swarm in the summer of 2000 .

However, there has long been a debate on whether earthquakes can be tidally triggered. While some study results demonstrate either a weak connection or no connection between the tidal variations and earthquake occurrence (Schuster, 1897; Heaton, 1982; Vidale et al., 1998), others provide very strong arguments for the existence of tidal triggering. For example, Métivier (2009) found a clear connection between the tidal variations and earthquake occurrence by analyzing the global earthquakes; Thomas et al. (2009) observed very strong evidence of tidal triggering of tremors.

A fascinating subject in recent study is the precursory pattern of the tidal triggering of earthquakes. Studies on some regions show that there are precursory effects of tidal triggering before large earthquakes. For example, studies by Tanaka $(2006,2010)$ have shown that a precursory connection be- 
tween the tidal variations and earthquake occurrence was found for several to ten years before some large earthquakes in the Sumatra region; a study on the Longmen Shan region (Li and $\mathrm{Xu}, 2012$ ) has shown that a precursory connection appeared about $5 \mathrm{yr}$ before the Wenchuan M8.0 earthquake. However, some other studies show different results. For example, a study by Vidale et al. (1998) demonstrates that only a weak connection between the tidal variations and earthquake occurrence was found on Calaveras Fault for the period of 1969 to 1994; studies by Luo et al. (2002) also show either no effect or weak effect of tidal triggering of earthquakes before large earthquakes in some regions of China. Seismologists have not exactly known the reason for this so far. Therefore, further studies on this topic are quite necessary.

In this paper, we investigate the tidal triggering of earthquakes in the Liyang, Wunansha, Cangshan, Wenan, Luquan and Yaoan regions of China. We concentrate on what the differences in precursory pattern of tidal triggering among these regions are and why these differences exist.

\section{Theoretical earth tide}

Generally speaking, the earth tide comprises two constituents: one is called the solid earth tide that influences the solid strata, created by the attraction of the Moon and Sun, the other is the ocean tide. In the vicinity of the ocean edges, we have to consider the effect of ocean loading because the effect of ocean tide is sometimes much larger as compared with that of solid earth tide. Therefore, ignoring the effect of ocean tide will bring about an incorrect conclusion. In the present study, the effect of ocean loading is considered for all the study regions to avoid this incorrect conclusion.

The theoretical earth tide stress is gained by making computations using the Preliminary Reference Earth Model (PREM) (Dziewonski and Anderson, 1981) and the ocean tide model, NAO.99b (Matsumoto et al., 2000). In order to get reliable computation results, the PREM we use has a slight modification (Tsuruoka et al., 1995): the top $6 \mathrm{~km}$ layer is replaced by a solid layer of $V_{\mathrm{p}}=5.7 \mathrm{~km} \mathrm{~s}^{-1}, V_{\mathrm{s}}=$ $3.38 \mathrm{~km} \mathrm{~s}^{-1}$ and $\rho=2.6 \mathrm{~g} \mathrm{~cm}^{-3}$ (Fu and Liu, 1991). In addition, to obtain the accurate value of tide stress, the calculations are done at the depths of the earthquake hypocenter (Tsuruoka et al., 1995).

As to the tidal stress components, some researchers use shear stress on the fault plane (Mohler, 1980; Heaton, 1982), the trace of stress tensor (Tsuruoka et al., 1995), tidal compressional stresses at the regional tectonic stress orientations (Tanaka et al., 2004) and Coulomb stress amplitude (Cochran et al., 2004) as tidal stress components. Different tidal stress components have their respective characteristic: the shear stress is not dependent on the choice of the fault plane due to the symmetry of the stress tensor, while for the normal stress it is not easy to distinguish the fault plane from the two nodal planes (Tanaka et al., 2002); the trace of stress tensor that denotes confining stress is not variant with coordinate rotation (Tanaka et al., 2002); the Coulomb stress depends on combination of the shear and normal stresses on the fault planes (Cochran et al., 2004); the tidal compressional stress at the regional tectonic stress orientation dose not depend on the focal mechanisms, and can be used in the regions where focal mechanisms are obtainable for only few seismic events. When we choose tidal stress component in the present study, it is necessary to consider whether we can gain credible triggering statistics. However, in our study regions, focal mechanisms are not obtainable for many small seismic events, which decreased the number of seismic events for statistical test if we use the shear stress on the fault plane, the trace of stress tensor or Coulomb stress amplitude as tidal stress components. According to the study by Tanaka et al. (2004), seismic events are inclined to happen when the earth tidal stress is superimposed on the regional tectonic stress. Thus, we use the tidal compressional stress at the regional tectonic stress orientations (which are the greatest compressive stress directions) as tidal stress components (calculations are done at the location of hypocenter) with the aim of gaining an adequate number of seismic events for statistical test (the azimuths of tectonic stress orientation of the Liyang, Wunansha, Cangshan and Wenan regions are $92^{\circ}, 87^{\circ}, 72^{\circ}, 66^{\circ}$, respectively, according to the study by Xie et al. (2004), and the azimuths of tectonic stress orientation of the Luquan and Yaoan regions are $148^{\circ}$ and $165^{\circ}$, respectively, according to the study by Qian et al. (2011)).

\section{Method of statistical test}

The method of examining tidal triggering of earthquakes is as follows (Tanaka et al., 2002).

First, we calculate tidal stress components at the location of hypocenter, and allocate the origin time of each earthquake to a phase angle of tidal stress. Making use of the stress maximum (the maximum of tidal compressional stress at the regional tectonic stress orientations in our study) closest to the origin time of earthquake, we allocate the maximum to the tidal stress phase angle of $0^{\circ}$. We allocate the preceding minimum to $-180^{\circ}$, and following minimum to $180^{\circ}$. Then we linearly partition the time interval between these phases into smaller time segments to allocate other phase angles.

Second, utilizing the tidal phase angle defined above, we investigate whether or not seismic events stochastically happen relative to the change of tidal stress by applying Schuster's test (Schuster, 1897; Heaton, 1982; Tsuruoka et al., 1995; Wilcock, 2001; Tanaka et al., 2002). The Schuster's test presented a parameter $p$ defined as the probability of a stochastic earthquake phase distribution, which denotes the significance level to decline the null hypothesis of a stochastic earthquake phase distribution. Thus, a lesser $p$ value means a closer connection between the tidal variations and 
earthquake occurrence. In the present study, we treat $p \leq 5 \%$ as the limit value to estimate the significant connection between tidal variations and earthquake occurrence (Tanaka et al., 2002; Stroup et al., 2007).

\section{Crustal heterogeneity and the calculation of scattering coefficient}

\subsection{Crustal heterogeneity}

In some regions of the earth's crust, there are many cracks, faults and high- or low-density bodies. All these elements make the earth's crust heterogeneous. The more such elements there are in these regions, the stronger the heterogeneity is.

In fact, the heterogeneities in certain areas are related to the formation of the fracture and rock systems during tectonic movement. Of the regions where we analyzed tidal triggering of earthquakes in the present study, the Liyang and Wunansha regions are located in the lower Yangtze block of China (Fig. 1), and have the same Pre-Sinian basements. The fracture and rock systems in the Liyang and Wunansha regions were developed in different ways during the Late Paleozoic and Early Mesozoic (Ye et al., 2006), which make the heterogeneities in these two regions different. The Cangshan and Wenan regions are located in the North China Block (Fig. 1), and have the same Archaean to Early Proterozoic crystalline basement. The heterogeneity in the Cangshan region is different from that in the Wenan region because of the different ways in which the fracture and rock systems were developed during the Mesozoic and Cenozoic (Liu et al., 2004b). The Luquan and Yaoan regions are situated in the upper Yangtze Block of inland area (Fig. 2), and have the same Pre-Sinian basements. The heterogeneity in the Luquan region is different from that in the Yaoan region due to the different ways in which the fracture and rock systems were developed during the late Cenozoic (Shen et al., 1998).

The heterogeneity in the earth's crust can be evaluated by analyzing seismic wave attenuation. According to $\mathrm{Wu}$ and Aki (1988), seismic wave energy attenuation is due to two major considerations: scattering at heterogeneities in the crust and intrinsic absorption caused by the anelasticity of crustal medium. Wu and Aki (1988) defined $B_{0}=\eta_{\mathrm{s}} /\left(\eta_{\mathrm{s}}+\eta_{\mathrm{a}}\right)$ as the proportion of scattering energy loss to total energy attenuation of seismic waves, where $B_{0}$ is called the seismic albedo, $\eta_{\mathrm{s}}$ is the scattering coefficient of the medium, which quantifies the scattering loss of energy during a wave cycle, and $\eta_{\mathrm{a}}$ is the absorption coefficient, which quantifies intrinsic absorption loss of energy during a wave cycle. Wu and Aki (1988) also defined extinction length, $L_{\mathrm{e}}$, as the distance within which the principal S-wave energy is reduced by $e^{-1}$. The inverse of the $L_{\mathrm{e}}$ and the coefficients $\eta_{\mathrm{s}}$ and $\eta_{\mathrm{a}}$ are related by the equation $L_{\mathrm{e}}^{-1}=\eta_{\mathrm{s}}+\eta_{\mathrm{a}}$. Wu and Aki (1988) believed that heterogeneity can be eval-

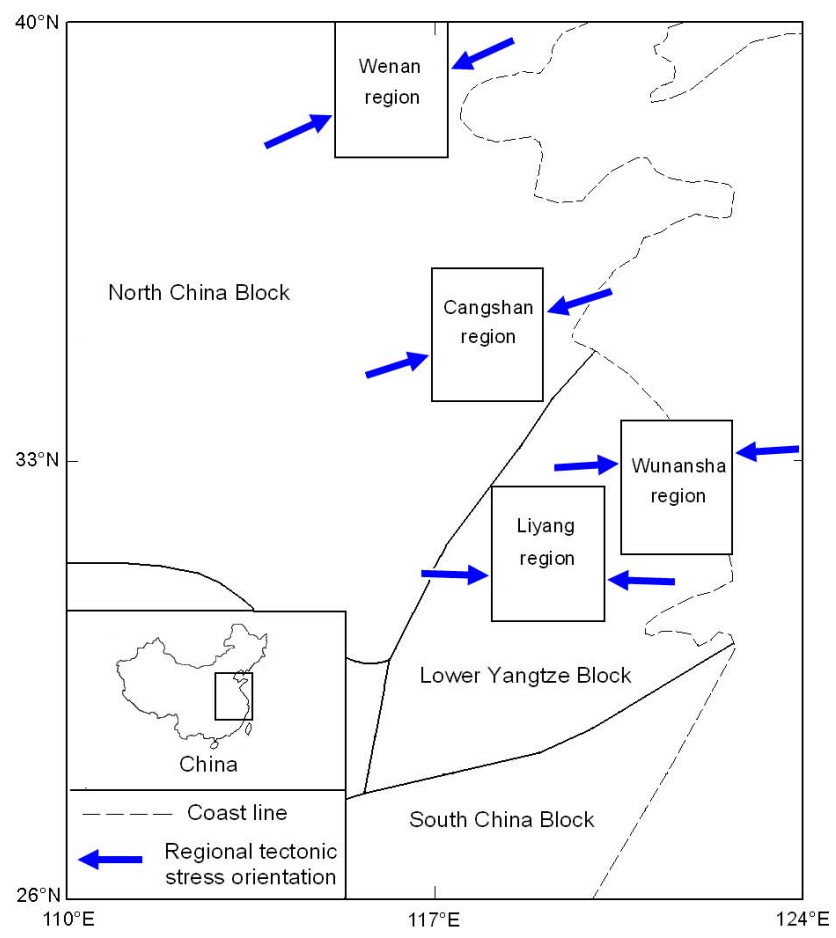

Fig. 1. Locations of the four study regions and the regional tectonic stress orientations. The Liyang and Wunansha regions are located in the lower Yangtze block of China, while the Cangshan and Wenan regions are located in the North China Block. The azimuths of tectonic stress orientation (the greatest compressive stress direction) of the Liyang, Wunansha, Cangshan and Wenan regions are $92^{\circ}, 87^{\circ}, 72^{\circ}$ and $66^{\circ}$, respectively, according to the study by Xie et al. (2004).

uated by assessing scattering loss of energy of the seismic wave, and the scattering coefficient $\eta_{\mathrm{s}}$ can be taken as a parameter to estimate this heterogeneity.

In this paper, in order to simplify the problem, we assume that the variations of heterogeneity in each region have been negligible since 1970 , and the heterogeneity is evaluated by the average $\eta_{\mathrm{s}}$ value.

\subsection{The calculation of scattering coefficient}

One of the effective methods of calculating $\eta_{\mathrm{s}}$ is the multiple lapse time window analysis (i.e., MLTWA), introduced by Hoshiba et al. (1991) and Fehler et al. (1992). The MLTWA is established on the following observational facts: the direct $S$ wave, whose amplitude is determined by the total attenuation coefficient of the crustal rock, dominates the first segment of S-wave; S-coda primarily comprises the scattering S-wave, whose amplitude is determined by the scattering coefficient of the crustal rock. Therefore, in the MLTWA, the seismogram is partitioned into three consecutive time segments: the first segment begins at the arrival of the direct $\mathrm{S}$-wave and finishes at the termination of the early coda wave; the second segment comprises the center section of the coda; the 


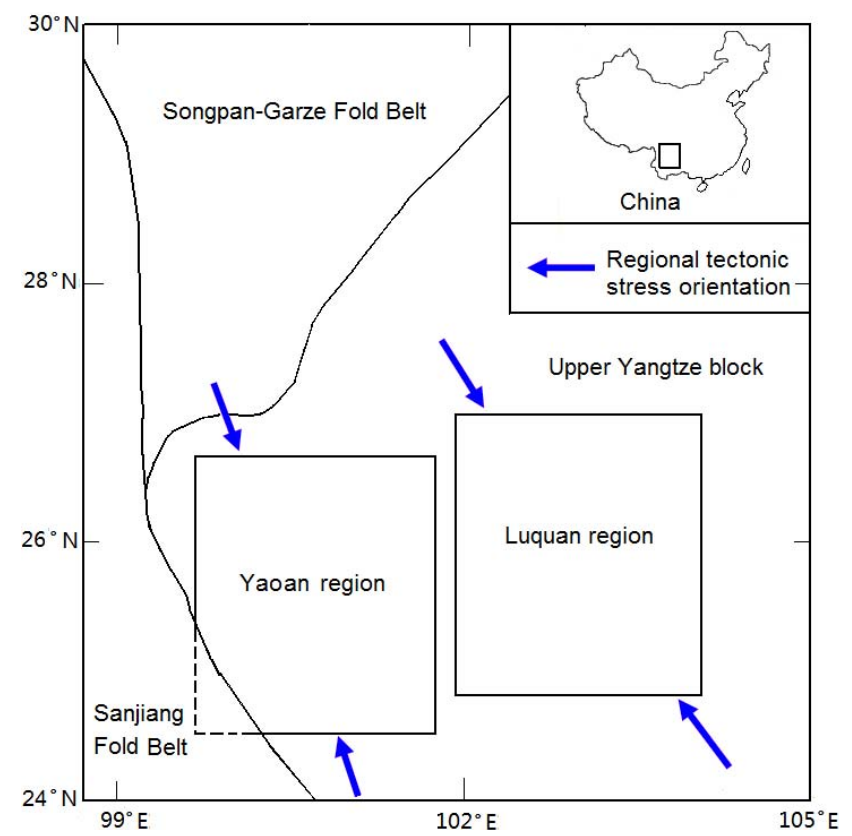

Fig. 2. Locations of the Luquan and Yaoan regions and the regional tectonic stress orientations. The azimuths of tectonic stress orientation (the greatest compressive stress direction) of the Luquan and Yaoan regions are $148^{\circ}$ and $165^{\circ}$, respectively, according to the study by Qian et al. (2011).

third segment comprises the posterior section of coda wave. By comparing the integrated energy densities derived from observational data with that derived from theoretical formulation for the above different time segments, the scattering coefficient and the absorption coefficient can be separately obtained.

Specifically, we use the following steps to obtain scattering coefficient.

Firstly, we define the three consecutive time windows (see Fig. 3) as 0-15, 15-30 and 30-45 s gauged from the S-wave arrival (Ugalde et al., 2007) in order that the three consecutive time windows can correspond to the above mentioned three segments of S-wave. The seismographs are filtered by a 10-order Butterworth band-pass filter for following six frequency bands: $1-2 \mathrm{~Hz}, 2-4 \mathrm{~Hz}, 4-8 \mathrm{~Hz}, 8-12 \mathrm{~Hz}, 12-18$, $18-26 \mathrm{~Hz}$. The hypocenter distance for an event is $r$.

Secondly, we calculate the integrated observed energy density and the integrated theoretical energy density. Using the three consecutive time windows above, the theoretical energy density, expressed by Zeng et al. (1991), is integrated. The integral of the observed energy density is obtained by making measurement of the mean squared amplitudes (Akinci and Eyidoan, 2000). In order to correct for the source, site effects, we use the Aki's coda normalization way (Aki, 1980), in which the reference time window we choose is 50$55 \mathrm{~s}$ (see Fig. 3). In addition, the energy correction for geometrical spreading is calculated by multiplying with $4 \pi r^{2}$.

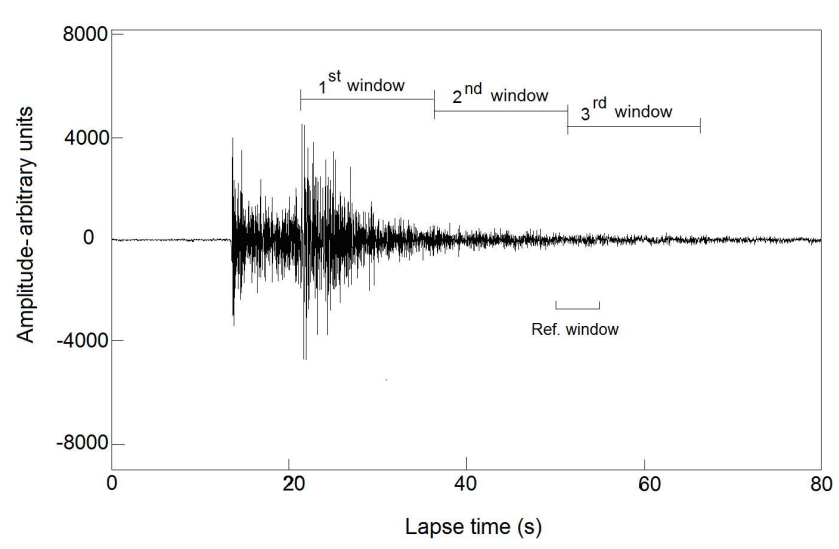

Fig. 3. Seismogram of an event (200404271343264.JS) in Liyang region. The three consecutive time windows and the reference time window are displayed by the horizontal lines.

Thirdly, we compare the integrated energy densities derived from observational data with that derived from theoretical formulation to obtain the best-fitting values of $B_{0}$ and $L_{\mathrm{e}}^{-1}$. The fitting errors are calculated by the following equation (Bianco et al., 2002):

$M\left(B_{0}, L_{\mathrm{e}}^{-1}\right)=\sum_{k=1}^{N} \sum_{i=1}^{3}\left(\operatorname{Em}_{i}\left(r_{k}\right)-\operatorname{Ec}_{i}\left(r_{k}\right)\right)^{2}$,

where $\operatorname{Em}_{i}\left(r_{k}\right)$ and $\operatorname{Ec}_{i}\left(r_{k}\right)$ are the integrated observed energy density and the integrated theoretical energy density, respectively, $N$ is the number of data points, $i$ corresponds to the time window. The minimum $M\left(B_{0}, L_{\mathrm{e}}^{-1}\right)$, which corresponds to the best-fitting values of $B_{0}$ and $L_{\mathrm{e}}^{-1}$ in the meaning of least square estimate, is determined by using the grid search method. The error of $B_{0}$ and $L_{\mathrm{e}}^{-1}$ is estimated by using $F$ distribution.

Finally, based on the best-fitting values of $B_{0}$ and $L_{\mathrm{e}}^{-1}$, the scattering and absorption coefficients are obtained from the two previously given equations $B_{0}=\eta_{\mathrm{s}} /\left(\eta_{\mathrm{s}}+\eta_{\mathrm{a}}\right)$ and $L_{\mathrm{e}}^{-1}=$ $\eta_{\mathrm{s}}+\eta_{\mathrm{a}}$.

\section{Data}

We analyze the tidal triggering of earthquakes within four regions in coastal area and two regions in inland area (the shortest distance from the ocean margin is about $700 \mathrm{~km}$ ) using epicenter data derived from the China Earthquake Administration. These regions are seismically active regions; however, the large earthquakes rarely occur in these regions so that we are able to analyze the changes in the connection between the tide and earthquake occurrence before certain large earthquakes. Besides, we divided these regions into several groups according to the location of their tectonic unit, which will help us compare one case with another within the same tectonic unit. For the four regions named as the 
Liyang, Wunansha, Cangshan and Wenan regions in coastal area, the Liyang and Wunansha regions are located in the lower Yangtze block, while the Cangshan and Wenan regions are located in the North China Block (see Fig. 1); thus, we divide these four regions into two groups: the first group is the Liyang and Wunansha regions, while the second group is the Cangshan and Wenan regions. As for the Luquan and Yaoan regions situated in the upper Yangtze Block of inland area (see Fig. 2), we named these two regions the third group.

For the first group of cases, we examine a total of 871 earthquakes in the Liyang and Wunansha regions during 1970-2000 above a magnitude of completeness of $M_{\mathrm{L}}=2.4$ (Fig. $4 \mathrm{a}$ and b). During this time, both of these regions experienced large earthquakes, the 9 July $1979\left(M_{\mathrm{s}}=6\right)$ and 21 May $1984\left(M_{\mathrm{s}}=6.2\right)$ earthquakes in the Liyang and Wunansha regions, respectively. For the second group, we examine a total of 712 earthquakes in the Cangshan and Wenan regions during 1980-2010 above a magnitude of completeness of $M_{\mathrm{L}}=2.2$ (Fig. $4 \mathrm{c}$ and d). During this time, both of these regions experienced destructive earthquakes, the 20 September $1995\left(M_{\mathrm{S}}=5.2\right)$ and 4 July $2006\left(M_{\mathrm{S}}=5.1\right)$ earthquakes in the Cangshan and Wenan regions, respectively. For the third group, we examine a total of 4042 earthquakes in the Luquan region during 1970-1992 (Fig. 4e) and in the Yaoan region during 1975-2005 above a magnitude of completeness of $M_{\mathrm{L}}=2.4$ (see Fig. 4f, because a small part in the lower left-hand corner in this region belongs to another tectonic unit (also see Fig. 2), we eliminated this part). The Luquan region experienced the 18 April $1985\left(M_{\mathrm{S}}=6.3\right)$ earthquake during 1970-1992. The Yaoan region experienced the 15 January $2000\left(M_{\mathrm{S}}=6.5\right)$ earthquake, and the 27 October $2001\left(M_{\mathrm{S}}=6.0\right), 21$ July 2003 $\left(M_{\mathrm{S}}=6.2\right), 16$ October $2003\left(M_{\mathrm{s}}=6.1\right)$ earthquakes during 1975-2005. The above completeness magnitudes were estimated by using Gutenberg-Richter formula (Wiemer and Wyss, 2000). Because clustering can lead to the erroneous results of statistical analysis (Young and Zurn, 1979), the clustered seismic events were excluded according to the way of Reasenberg (1985). In addition, because some artificial effects may arise either from different declustering algorithms (Huang, 2008) or from the selection of RTL model parameters (Huang, 2005, 2006), it is necessary to make some test to ensure the reliability of the declustering process. Our test results indicated that the artificial effects from different declustering algorithms (Gardner and Knopoff, 1974; Reasenberg, 1985 ) and the selection of RTL model parameters (Huang, $2005,2006)$ can be negligible.

As to the data set for calculating the heterogeneities, for the first group, we adopt 109 digital seismograms from local events that occurred between 1999 and 2010 in the Liyang and Wunansha regions (see Fig. 4a and b; we choose the window of 1999-2010 for calculating crustal heterogeneity due to the limitation of the available digital data.). The events had focal depths between 7 and $28 \mathrm{~km}$ and magnitudes ranging from $M_{\mathrm{L}}=2.5$ to 3.8 . The events were recorded at 19 dig- ital seismic stations in these regions. For the second group, we adopt 113 digital seismograms from local events that occurred between 1999 and 2010 in the Cangshan and Wenan regions (see Fig. $4 \mathrm{c}$ and d). The events had focal depths between 10 and $28 \mathrm{~km}$ and magnitudes ranging from $M_{\mathrm{L}}=2.4$ to 3.6. The events were recorded at 21 digital seismic stations in these regions. For the third group, we adopt 126 digital seismograms from local events that occurred between 1999 and 2010 in the Luquan and Yaoan regions (see Fig. 4e and f). The events had focal depths between 10 and $28 \mathrm{~km}$ and magnitudes ranging from $M_{\mathrm{L}}=2.6$ to 3.7 . The events were recorded at 8 digital seismic stations in these regions.

\subsection{Results and analysis}

\subsection{Heterogeneities of the six regions}

On the basis of the digital seismograms mentioned above, we first calculated the integrated observed energy density and the integrated theoretical energy density. Then we use grid search method to obtain the best-fitting values of $B_{0}$ and $L_{\mathrm{e}}^{-1}$. Finally, we obtain the scattering coefficients $\eta_{\mathrm{s}}$ of the six study regions. Figure 5 shows some examples of the fitting results for partial frequency bands in the six regions, in which the $90 \%$ confidence regions are represented by cross symbols, and the best-fitting values of $B_{0}$ and $L_{\mathrm{e}}^{-1}$ are represented by the circles. The full results of $B_{0}$ and $L_{\mathrm{e}}^{-1}$ for six frequency bands and the average scattering coefficients $\eta_{\mathrm{s}}$ (mathematic average) in the six regions are shown in the Tables 1, 2 and 3. From the tables we know that the average scattering coefficients $\eta_{\mathrm{s}}$ in the Liyang region and $\mathrm{Wu}-$ nansha region are 0.00624 and 0.00273 , respectively, the average scattering coefficients $\eta_{\mathrm{s}}$ in the Cangshan region and Wenan region are 0.01119 and 0.00187 , respectively, and the average scattering coefficients $\eta_{\mathrm{s}}$ in the Luquan region and Yaoan region are 0.01295 and 0.00205 , respectively. These results indicate that the heterogeneity in the Liyang region is stronger than in the Wunansha region, the heterogeneity in the Cangshan region is stronger than in the Wenan region, and the heterogeneity in the Luquan region is stronger than in the Yaoan region.

\subsection{The connection between the tidal variations and earthquake occurrence in the Liyang and Wunansha regions}

The temporal variations of $p$ value in the two regions were calculated by using the Schuster's test and the concept of a sliding window. To obtain reliable analysis results, we need enough number of seismic events $(>10)$ for Schuster's test (Schuster, 1897). Thus, we use the window length of 1200 days (each window comprises at least 21 earthquakes) and the step of 200 days. In the following study, we used the uniform sliding window length (i.e., 1200 days) and step length (i.e., 200 days) for the sake of easy comparison 
(a)

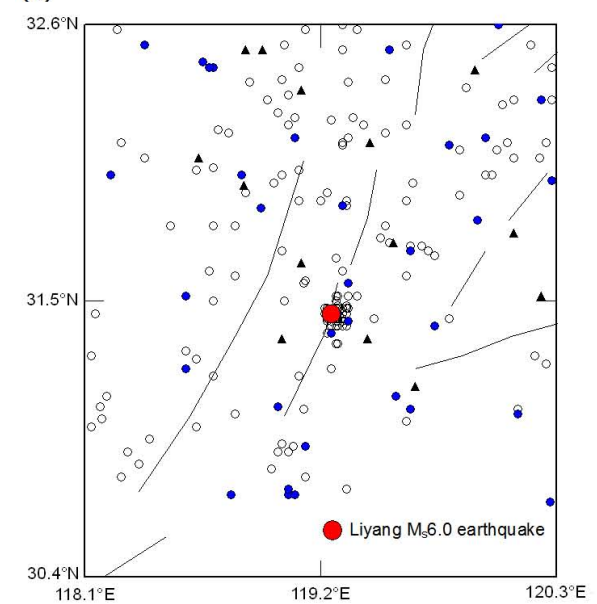

(c)

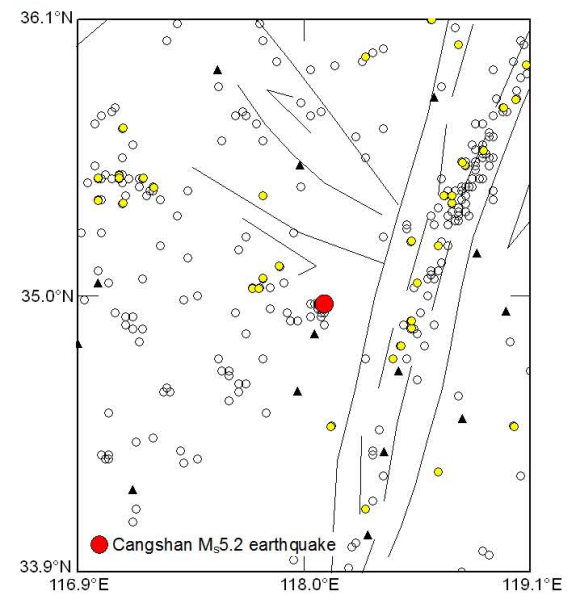

(e)

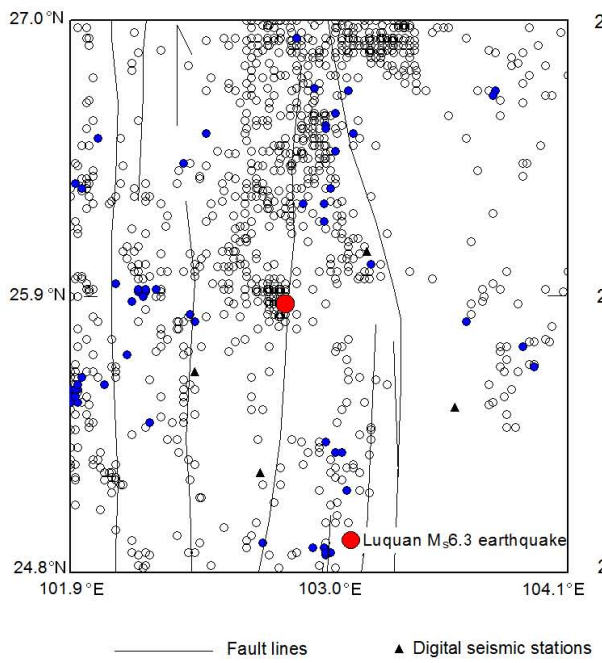

(b)

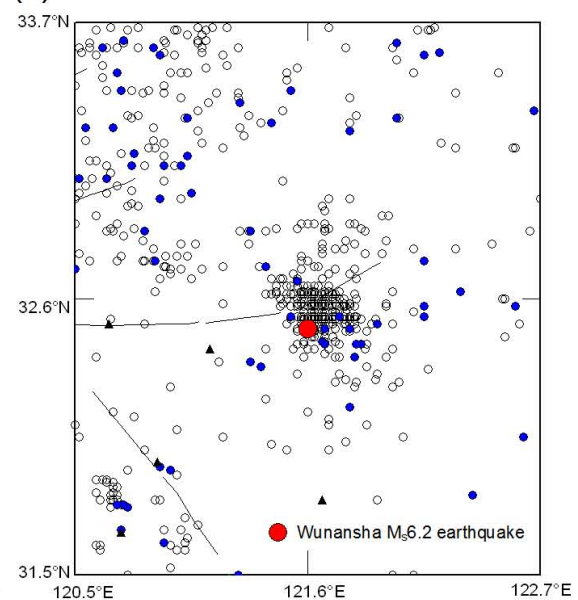

(d)

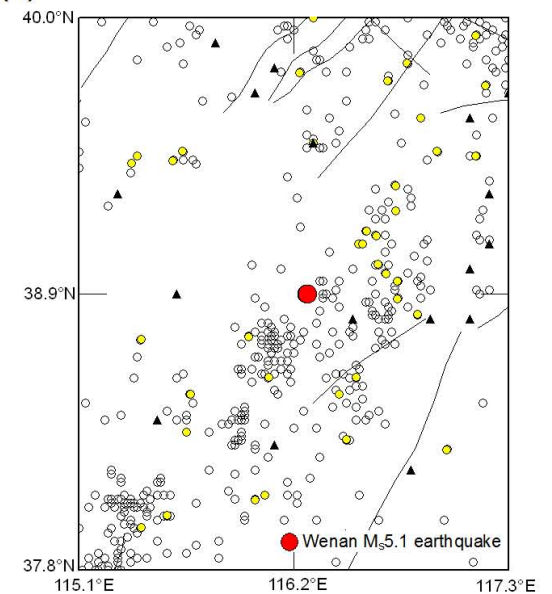

(f)

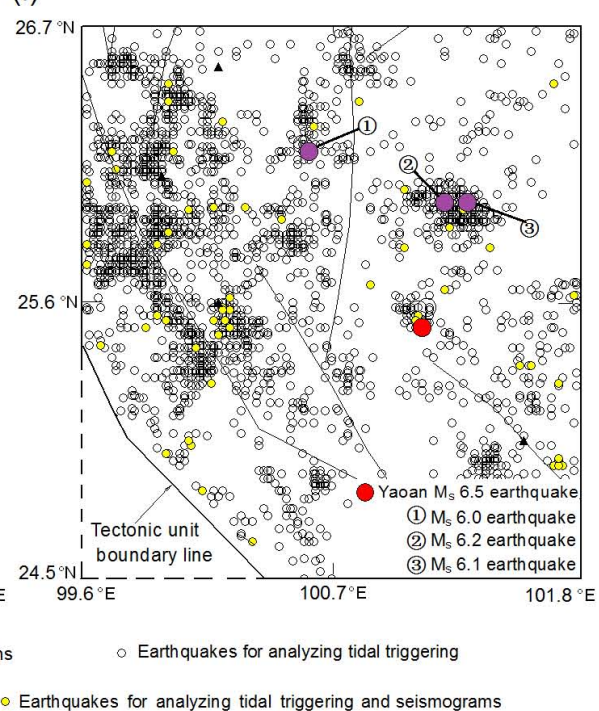

Fig. 4. The distribution of the seismic events (the mean location uncertainty of these events is $5 \mathrm{~km}$ ), fault lines and digital seismic stations. The blue dots indicate the earthquakes for analyzing seismograms, and the yellow dots indicate the earthquakes for analyzing tidal triggering and seismograms. (a) Liyang region. (b) Wunansha region. (c) Cangshan region. (d) Wenan region. (e) Luquan region. (f) Yaoan region. In the Liyang region, there is a fault zone named Maoshan fault zone. In the Cangshan region, there is a large fault zone named Tanlu fault zone. In the Luquan region, there is a large fault zone named Xiaojiang fault zone. In the Yaoan region, there is a fault zone named ChuxiongJianshui fault zone. 
(a)

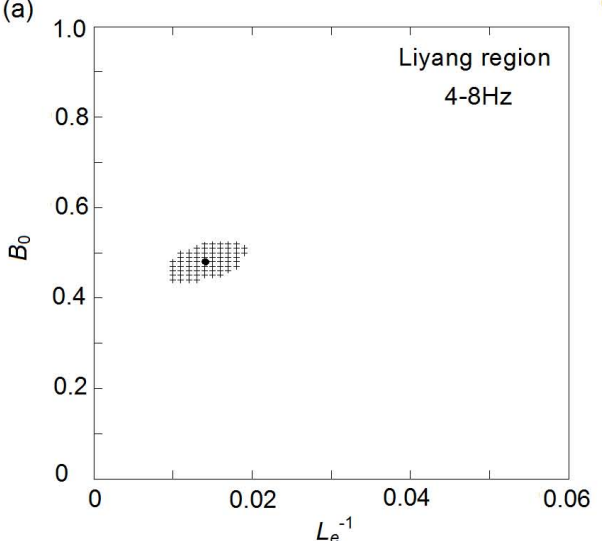

(c)

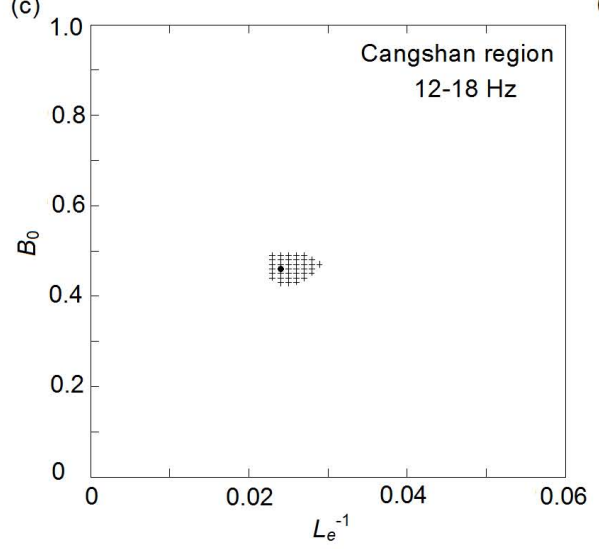

(e)

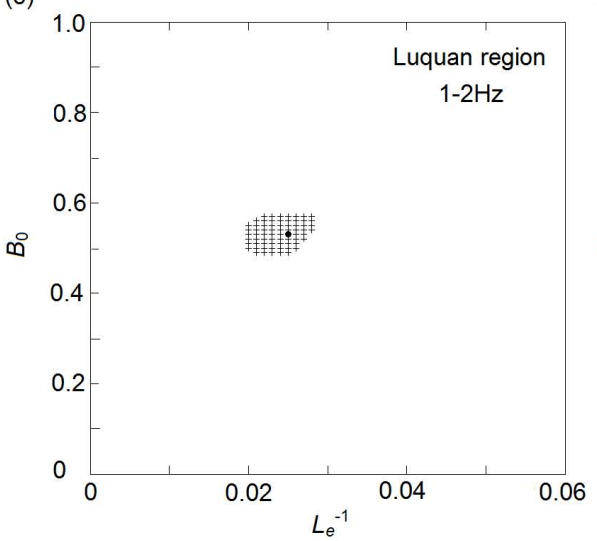

(b)

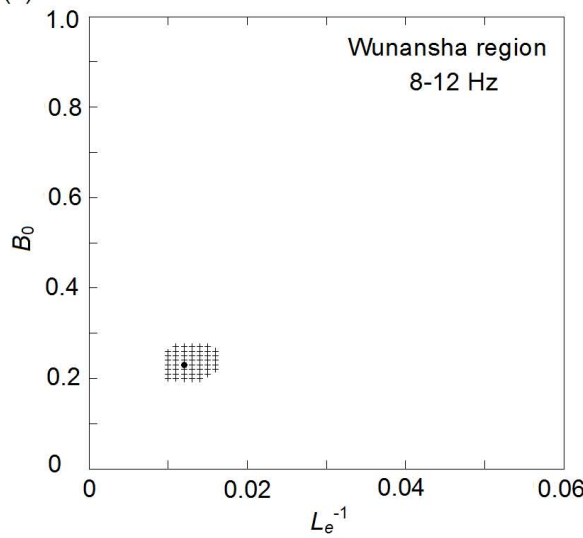

(d)
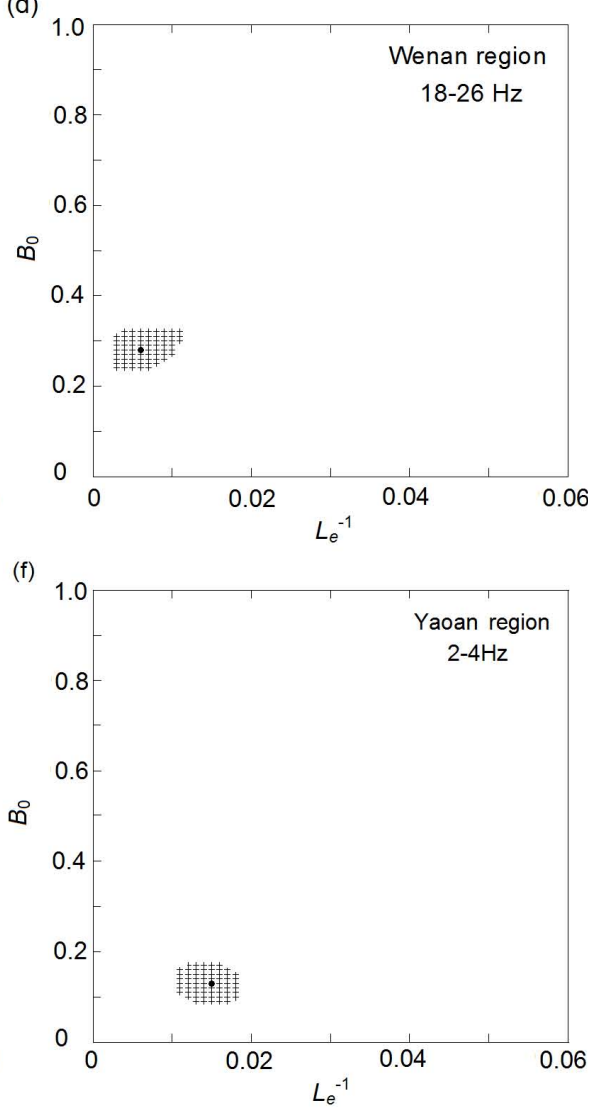

Fig. 5. Some examples of residual maps for partial frequency bands in the six regions. The $90 \%$ confidence regions are represented by cross symbols, and the pairs $B_{0}$ and $L_{\mathrm{e}}^{-1}$ which correspond to minimum residual are represented by circles.

among the results calculated from the uniform sliding window length and step length.

Figure 6a shows the temporal variation of the $p$ value in the Liyang region. As can be seen, the $p$ value fluctuated between 36.2 and $49.6 \%$ for the period 1970 to mid-1974. However, it began to decrease in late 1974. The minimum value it achieved before the Liyang $M_{\mathrm{s}}=6.0$ earthquake is $1.3 \%$. After the $M_{\mathrm{s}}=6.0$ earthquake, the $p$ value fluctuates between 31.5 and $50.6 \%$. This variation indicates that the tidal triggering of earthquakes is possible only at the time that the stress increases achieving a critical level before large rupture. Figure $6 \mathrm{~b}$ exhibits the phase angles frequency distribution during the period of 1600 days (about $4.5 \mathrm{yr}$ ) before the Liyang $M_{\mathrm{S}}=6.0$ earthquake. The result of Schuster's test shows a small $p$ value of $2.1 \%$, which indicates a higher confidence to decline the null hypothesis of a stochastic earthquake phase distribution, signifying that there is a statistically significant connection for this period. Because 
Table 1. Calculated results of seismic albedo $B_{0}$, inverse of extinction length $L_{\mathrm{e}}^{-1}$ and scattering coefficients $\eta_{\mathrm{s}}$ in the Liyang and Wunansha regions.

\begin{tabular}{lllllll}
\hline$F(\mathrm{~Hz})$ & \multicolumn{3}{c}{ Liyang region } & \multicolumn{3}{c}{ Wunansha region } \\
\cline { 2 - 6 } & $L_{\mathrm{e}}^{-1}$ & $B_{0}$ & $\eta_{\mathrm{s}}$ & $L_{\mathrm{e}}^{-1}$ & $B_{0}$ & $\eta_{\mathrm{s}}$ \\
\hline \multirow{2}{*}{$1-2$} & $0.015+0.003$ & $0.49+0.02$ & 0.00735 & $0.013+0.002$ & $0.23+0.02$ & 0.00299 \\
& -0.002 & -0.03 & & -0.003 & -0.01 & \\
$2-4$ & $0.013+0.002$ & $0.50+0.03$ & 0.00650 & $0.012+0.003$ & $0.24+0.02$ & 0.00288 \\
& -0.002 & -0.02 & & -0.002 & -0.03 & \\
$4-8$ & $0.014+0.003$ & $0.48+0.02$ & 0.00672 & $0.014+0.003$ & $0.23+0.02$ & 0.00322 \\
& -0.003 & -0.02 & & -0.003 & -0.02 & \\
$8-12$ & $0.012+0.002$ & $0.46+0.02$ & 0.00552 & $0.012+0.002$ & $0.23+0.02$ & 0.00276 \\
& -0.002 & -0.01 & & -0.002 & -0.02 & \\
$12-18$ & $0.013+0.002$ & $0.47+0.02$ & 0.00611 & $0.011+0.002$ & $0.21+0.02$ & 0.00231 \\
& -0.003 & -0.02 & & -0.002 & -0.03 & \\
$18-26$ & $0.011+0.003$ & $0.48+0.03$ & 0.00528 & $0.010+0.002$ & $0.22+0.02$ & 0.00220 \\
& -0.002 & -0.02 & & -0.002 & -0.02 & \\
Average & & & 0.00624 & & & 0.00273 \\
\hline
\end{tabular}

Table 2. Calculated results of seismic albedo $B_{0}$, inverse of extinction length $L_{\mathrm{e}}^{-1}$ and scattering coefficients $\eta_{\mathrm{s}}$ in the Cangshan and Wenan regions.

\begin{tabular}{lllllll}
\hline \multirow{2}{*}{$F(\mathrm{~Hz})$} & \multicolumn{3}{c}{ Cangshan region } & \multicolumn{3}{c}{ Wenan region } \\
\cline { 2 - 6 } & $L_{\mathrm{e}}^{-1}$ & $B_{0}$ & $\eta_{\mathrm{S}}$ & $L_{\mathrm{e}}^{-1}$ & $B_{0}$ & $\eta_{\mathrm{S}}$ \\
\hline \multirow{2}{*}{$1-2$} & $0.021+0.003$ & $0.52+0.04$ & 0.01092 & $0.007+0.002$ & $0.31+0.03$ & 0.00217 \\
& -0.003 & -0.03 & & -0.002 & -0.02 & \\
$2-4$ & $0.023+0.004$ & $0.49+0.03$ & 0.01127 & $0.006+0.001$ & $0.27+0.02$ & 0.00162 \\
& -0.003 & -0.03 & & -0.002 & -0.03 & \\
$4-8$ & $0.025+0.004$ & $0.51+0.02$ & 0.01275 & $0.006+0.002$ & $0.28+0.03$ & 0.00168 \\
& -0.003 & -0.03 & & -0.002 & -0.02 & \\
$8-12$ & $0.023+0.003$ & $0.49+0.03$ & 0.01127 & $0.007+0.002$ & $0.25+0.02$ & 0.00175 \\
& -0.002 & -0.02 & & -0.003 & -0.02 & \\
$12-18$ & $0.024+0.003$ & $0.46+0.03$ & 0.01014 & $0.009+0.003$ & $0.26+0.03$ & 0.00234 \\
& -0.003 & -0.03 & & -0.002 & -0.03 & \\
$18-26$ & $0.023+0.002$ & $0.47+0.02$ & 0.01081 & $0.006+0.002$ & $0.28+0.02$ & 0.00168 \\
& -0.003 & -0.03 & \multirow{2}{*}{0.01119} & -0.001 & -0.02 & \multirow{2}{*}{0.00187} \\
Average & & & 0.0119 & &
\end{tabular}

the maximum of phase angle frequency is found to be close to the angle $0^{\circ}$, in which the tidal compressional stress at the regional tectonic stress orientation is at its peak value, raising the possibility of seismic events, this significant connection before the Liyang $M_{\mathrm{S}}=6.0$ earthquake can be ascribed to the triggering effect of tidal stress.

Figure $6 \mathrm{c}$ shows the temporal variation of the $p$ value in the Wunansha region. The $p$ value fluctuated between 48.3 and $67.1 \%$ for the period 1970 to early 1979 . It began to decrease in mid-1979. The smallest $p$ value before the $\mathrm{Wu}-$ nansha $M_{\mathrm{S}}=6.2$ earthquake is $15.7 \%$, which is larger than the threshold. After the $M_{\mathrm{S}}=6.2$ earthquake, the $p$ value fluctuates between 51.3 and $75.1 \%$. Figure 6d shows the frequency distribution of tidal phase angles for the period of 1600 days before the Wunansha $M_{\mathrm{s}}=6.2$ earthquake. A $p$ value of $23.6 \%$, which is much larger than the threshold, is obtained. This result indicates that the confidence declining the null hypothesis of a stochastic earthquake phase distribution is lower and there is no statistically significant connection for this period.

Comparing the $p$ value in the Liyang region with that in the Wunansha region, we find that a significant connection ( $p \leq 5 \%$ ) appeared several years before the $M_{\mathrm{S}}=6.0$ earthquake in the Liyang region, while no significant connection appeared in the Wunansha region. These results suggest that there is a difference in the tidal triggering of earthquakes between these two regions. 
Table 3. Calculated results of seismic albedo $B_{0}$, inverse of extinction length $L_{\mathrm{e}}^{-1}$ and scattering coefficients $\eta_{\mathrm{s}}$ in the Luquan and Yaoan regions.

\begin{tabular}{lllllll}
\hline$F(\mathrm{~Hz})$ & \multicolumn{3}{c}{ Luquan region } & \multicolumn{3}{c}{ Yaoan region } \\
\cline { 2 - 6 } & $L_{\mathrm{e}}^{-1}$ & $B_{0}$ & $\eta_{\mathrm{s}}$ & $L_{\mathrm{e}}^{-1}$ & $B_{0}$ & $\eta_{\mathrm{s}}$ \\
\hline $1-2$ & $0.025+0.002$ & $0.53+0.02$ & 0.01325 & $0.011+0.002$ & $0.18+0.02$ & 0.00198 \\
& -0.003 & -0.03 & & -0.001 & -0.02 & \\
$2-4$ & $0.031+0.003$ & $0.41+0.02$ & 0.01271 & $0.015+0.002$ & $0.13+0.03$ & 0.00195 \\
& -0.002 & -0.02 & & -0.002 & -0.02 & \\
$4-8$ & $0.033+0.002$ & $0.40+0.03$ & 0.01320 & $0.025+0.002$ & $0.09+0.02$ & 0.00225 \\
& -0.003 & -0.02 & & -0.003 & -0.03 & \\
$8-12$ & $0.032+0.003$ & $0.41+0.02$ & 0.01312 & $0.021+0.002$ & $0.11+0.03$ & 0.00231 \\
& -0.002 & -0.02 & & -0.002 & -0.02 & \\
$12-18$ & $0.034+0.003$ & $0.38+0.02$ & 0.01292 & $0.011+0.002$ & $0.17+0.02$ & 0.00187 \\
& -0.002 & -0.03 & & -0.003 & -0.02 & \\
$18-26$ & $0.032+0.002$ & $0.39+0.02$ & 0.01248 & $0.013+0.003$ & $0.15+0.02$ & 0.00195 \\
& -0.003 & -0.02 & \multirow{2}{*}{0.0 .02} & -0.03 & \multirow{2}{*}{0.00205} \\
\hline
\end{tabular}

\subsection{The connection between the tidal variations and earthquake occurrence in the Cangshan and Wenan regions}

The temporal variations of the $p$ value in these two regions were calculated by the above method.

Figure 7a shows the temporal variation of $p$ value in the Cangshan region. We note that the $p$ value fluctuated between 39.3 and $64.6 \%$ for the period 1980 to late 1990 . The $p$ value began to decrease in early 1991 . The smallest value it achieved is $0.82 \%$. Then the $p$ value marginally increased just before the Cangshan $M_{\mathrm{s}}=5.2$ earthquake. After the $M_{\mathrm{S}}=5.2$ earthquake, the $p$ value fluctuates between 34.3 and $66.7 \%$. Figure $7 \mathrm{~b}$ shows the frequency distribution of tidal phase angles for the period of 1600 days before the Cangshan $M_{\mathrm{s}}=5.2$ earthquake (we use a uniform 1600 days for the non-sliding window due to the following two reasons: one is that the period with $p<5 \%$ before several large earthquakes in our study cases is about $4.5 \mathrm{yr}$, the other is for easy comparison among the results calculated from the non-sliding window.). A small $p$ value of $0.98 \%$, which is much smaller than the threshold, is obtained, indicating a higher confidence to decline the null hypothesis of a stochastic earthquake phase distribution and a statistically significant connection for this period. The maximum of phase angle frequency is found to be close to the angle $0^{\circ}$, in which the tidal compressional stress at the regional tectonic stress orientation is at its peak value, increasing the possibility of seismic events. This phenomenon indicates that the significant connection before the Cangshan $M_{\mathrm{S}}=5.2$ earthquake is not stochastic, but can be ascribed to the triggering effect of tidal stress.

Figure 7c shows the temporal variation of the $p$ value in the Wenan region. The $p$ value fluctuated between 40.1 and
$69.8 \%$ for the period 1980 to mid-2002. However, the decrease is not obvious before the Wenan $M_{\mathrm{s}}=5.1$ earthquake. Figure $7 \mathrm{~d}$ shows the frequency distribution of tidal phase angles for the period of 1600 days before the Wenan $M_{\mathrm{S}}=5.1$ earthquake. A $p$ value of $31.6 \%$, which is much larger than the threshold, is obtained. This result indicates that the confidence declining the null hypothesis of a stochastic earthquake phase distribution is much low and there is no statistically significant connection for this period.

Comparing the $p$ value in the Cangshan region with that in the Wenan region, the difference in the tidal triggering is obvious.

\subsection{The connection between the tidal variations and earthquake occurrence in the Luquan and Yaoan regions}

The temporal variations of the $p$ value in these two regions were calculated by the above method.

The temporal variation of $p$ value in the Luquan region is shown in Fig. 8a. As can be seen from the illustration, the $p$ value fluctuated between 41.2 and $65.4 \%$ for the period 1970 to late 1980 . The $p$ value began to decrease in early 1981. The smallest value it achieved is $0.62 \%$. After the $M_{\mathrm{S}}=6.3$ earthquake, the $p$ value fluctuates between 40.3 and $73.1 \%$. Figure $8 \mathrm{~b}$ shows the frequency distribution of tidal phase angles for the period of 1600 days before the Luquan $M_{\mathrm{S}}=6.3$ earthquake. A small $p$ value of $0.75 \%$, which is much smaller than the threshold, is obtained, indicating a higher confidence to decline the null hypothesis of a stochastic earthquake phase distribution and a statistically significant connection for this period. The maximum of phase angle frequency is found to be close to the angle $0^{\circ}$, in which the tidal compressional stress at the regional tectonic stress orientation is at its peak value, enhancing the possibility of 
(a)

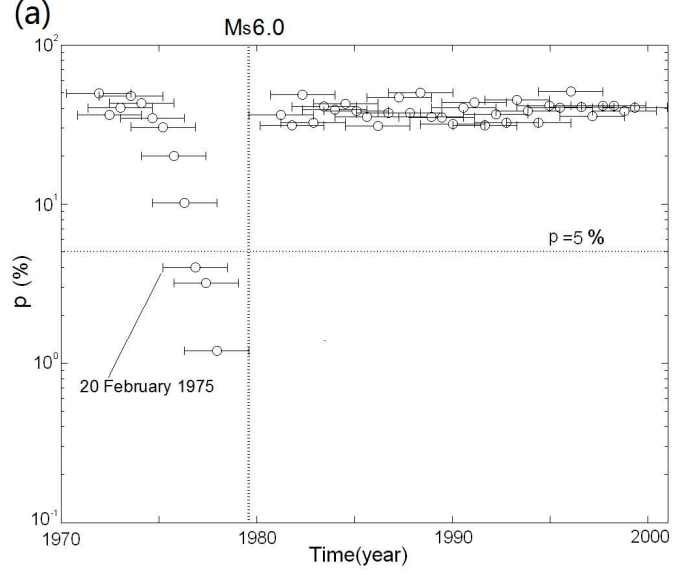

(c)

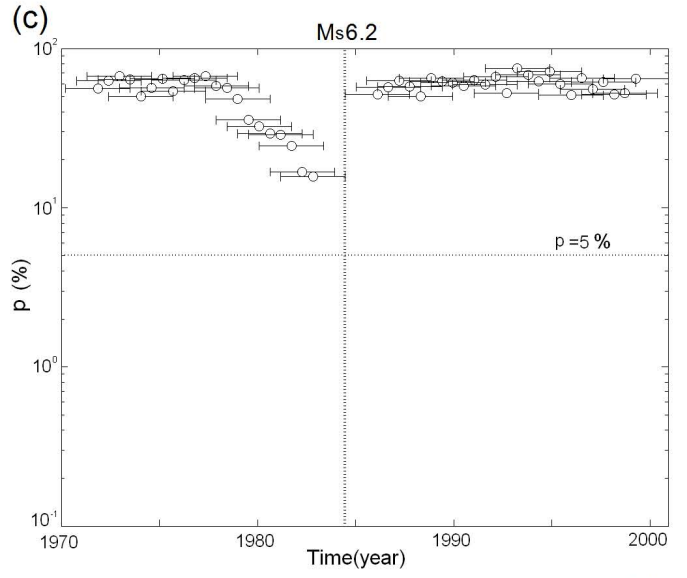

(b)

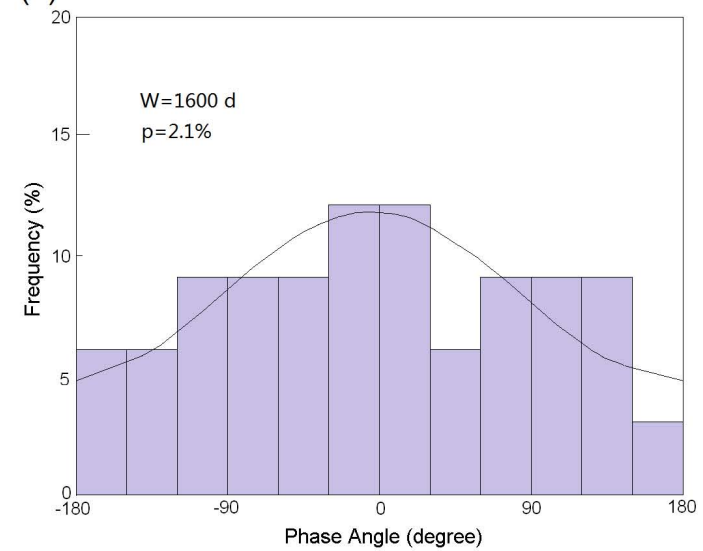

(d)

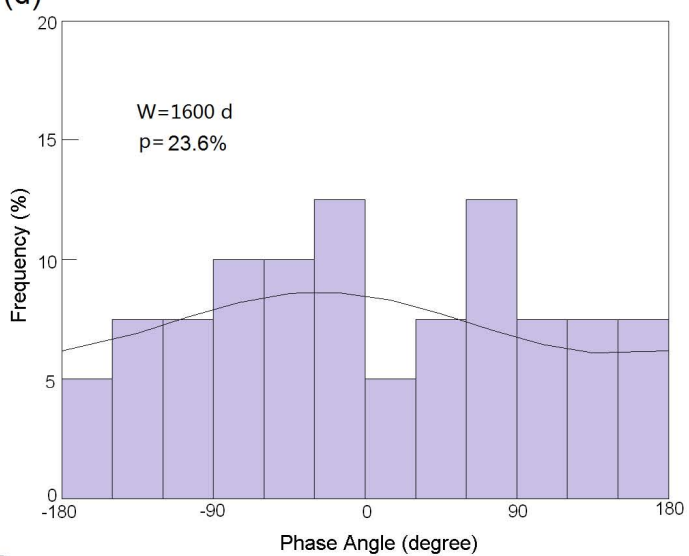

Fig. 6. (a) Variation of $p$ value with time in the Liyang region. The time window length, indicated by a horizontal line, is 1200 days, and the step length is 200 days. (b) Phase angle frequency change for events during the period of 1600 days before the Liyang $M_{\mathrm{S}}=6.0$ earthquake. The fine solid curve signifies a sinusoidal function which corresponds to the least square fit to the change. The fitting time window is a full period of sinusoidal function. (c) Variation of $p$ value with time in the Wunansha region. The time window length, indicated by a horizontal line, is 1200 days, and the step length is 200 days. (d) Phase angle frequency change for events during the period of 1600 days before the Wunansha $M_{\mathrm{S}}=6.2$ earthquake. The fine solid curve signifies a sinusoidal function which corresponds to the least square fit to the change. The fitting time window is a full period of sinusoidal function.

seismic events. This result indicates that the significant connection before the Luquan $M_{\mathrm{s}}=6.3$ earthquake can be ascribed to the triggering effect of tidal stress.

The temporal variation of the $p$ value in the Yaoan region is shown in Fig.8c. We see that the $p$ value fluctuated between 45.3 and $76.4 \%$ for the period 1975 to late 1995 . However, the decrease is not evident before the Yaoan $M_{\mathrm{s}}=6.5$ earthquake. After $M_{\mathrm{s}}=6.5$ earthquake, it increased little (in this period, several $M_{\mathrm{s}}=6.0$ or so earthquakes occurred in this region, however, we focus on the variation of $p$ value before $M_{\mathrm{s}}=6.5$ earthquake). Figure $8 \mathrm{~d}$ shows the frequency distribution of tidal phase angles for the period of 1600 days before the Yaoan $M_{\mathrm{s}}=6.5$ earthquake. A $p$ value of $28.4 \%$, which is much larger than the threshold, is obtained. This result indicates that the confidence declining the null hypothesis of a stochastic earthquake phase distribution is low and there is no statistically significant connection for this period.
Comparing the $p$ value in the Luquan region with that in the Yaoan region, the difference in the tidal triggering is also obvious.

\subsection{Examination of focal mechanism and depth differences}

Some studies have indicated that the tidal triggering of earthquakes is related to the type of focal mechanism (Tsuruoka et al., 1995; Tanaka et al., 2002; Cochran et al., 2004). Other studies have shown that it is also related to the depth of the seismic events (Heaton, 1975; Cochran et al., 2004). These study results suggest that in order to confirm the possible relationship between the tidal triggering and the heterogeneities, we should eliminate the influences of the focal mechanism types and depth on the above differences of tidal triggering. Therefore, it is necessary for us to discuss whether 
(a)

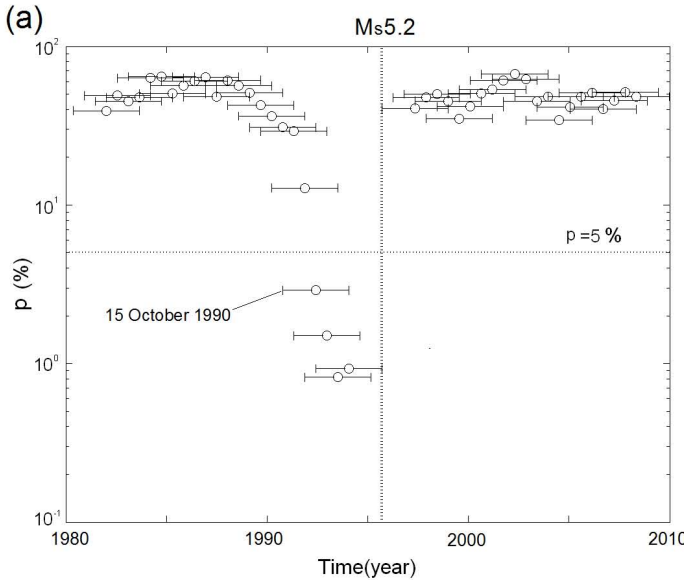

(c)

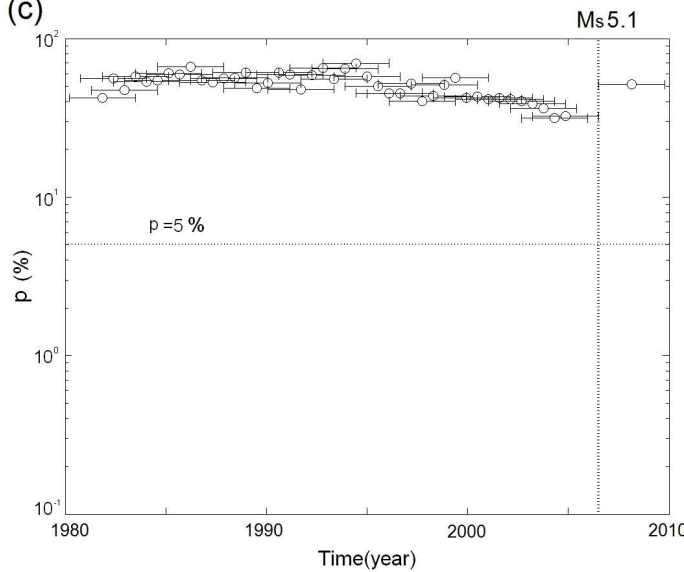

(b)

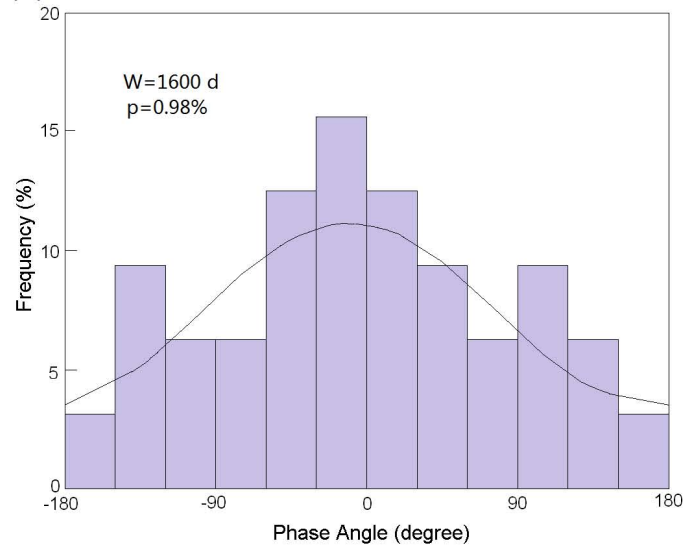

(d)

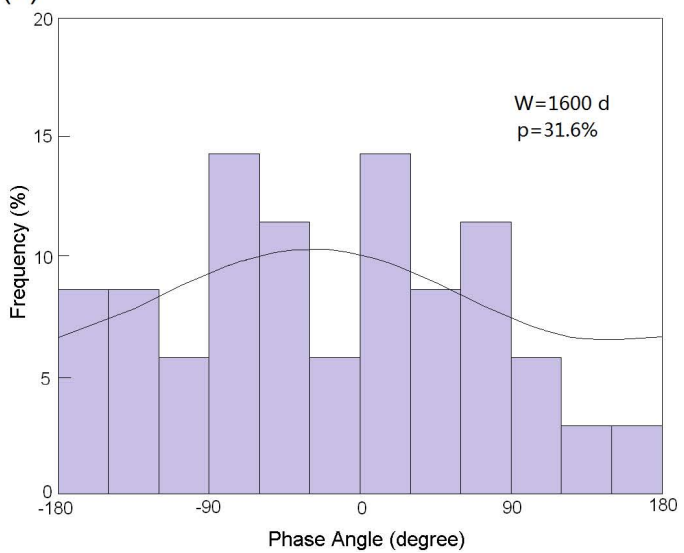

Fig. 7. (a) Variation of $p$ value with time in the Cangshan region. The time window length, indicated by a horizontal line, is 1200 days, and the step length is 200 days. (b) Phase angle frequency change for events during the period of 1600 days before the Cangshan $M_{\mathrm{S}}=5.2$ earthquake. The fine solid curve signifies a sinusoidal function which corresponds to the least square fit to the change. The fitting time window is a full period of sinusoidal function. (c) Variation of $p$ value with time in the Wenan region. The time window length, indicated by a horizontal line, is 1200 days, and the step length is 200 days. (d) Phase angle frequency change for events during the period of 1600 days before the Wenan $M_{\mathrm{S}}=5.1$ earthquake. The fine solid curve signifies a sinusoidal function which corresponds to the least square fit to the change. The fitting time window is a full period of sinusoidal function.

the types of focal mechanism and the depth of the seismic events are responsible for the above differences.

According to the studies by Tanaka et al. (2002), Tsuruoka et al. (1995) and Cochran et al. (2004), the strikeslip fault type is not susceptible to tidal triggering, while other types (normal, reverse, oblique) are possibly susceptible to tidal triggering. We calculated the statistics on the types of focal mechanisms (total of 138 earthquakes) for the first group of cases according to the published data (Liu et al., 2004a) and existing databases provided by the Research Center for Earthquake Prediction, Earthquake Administration of Jiangsu Province of China (EAJPC). We found that the susceptible types (normal, reverse, oblique) in the Liyang region and the Wunansha region are 77.3 and $76.5 \%$ of the above data, indicating that the types in these two regions are very close to each other. Therefore, the type of focal mechanism is less likely to be responsible for the above difference. Further- more, the focal mechanism solution in the Liyang and $\mathrm{Wu}-$ nansha regions shows that the dominant azimuth of the principal stress axes is distributed between 73 and $105^{\circ}$, which are adjacent to the azimuths of the regional tectonic stress of these two regions, indicating that the focal mechanism is related to the regional tectonic stress.

For the second group of cases, we produced the statistics on the types of focal mechanisms (total 131 earthquakes) according to the published data (Lan et al., 2005; Shan et al., 2007) and existing databases provided by the Institute of Geophysics, China Earthquake Administration, and the Research Center for Earthquake Prediction, EAJPC. The statistical results show that the susceptible types (normal, reverse, oblique) in the Cangshan region and the Wenan region are 72 and $74.6 \%$ of the above data, respectively, signifying that the type of focal mechanism is unlikely to be responsible for the above difference. Furthermore, the focal mechanism solution 
(a)

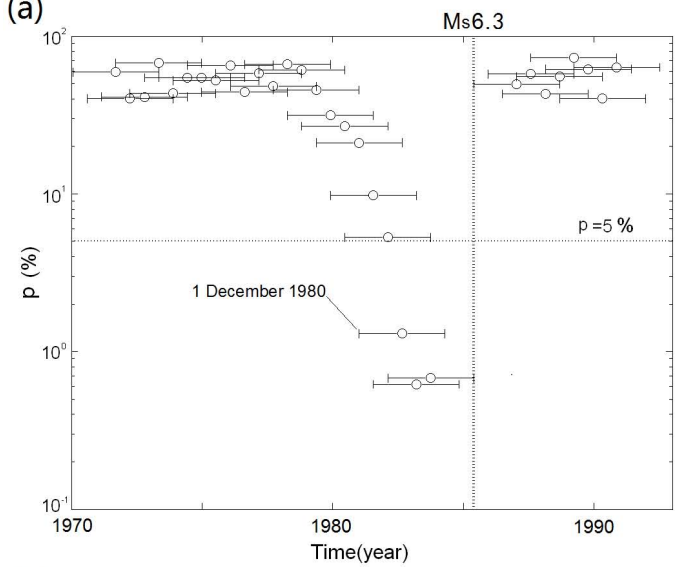

(c)

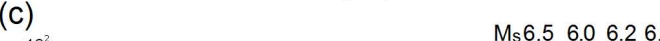

(b)

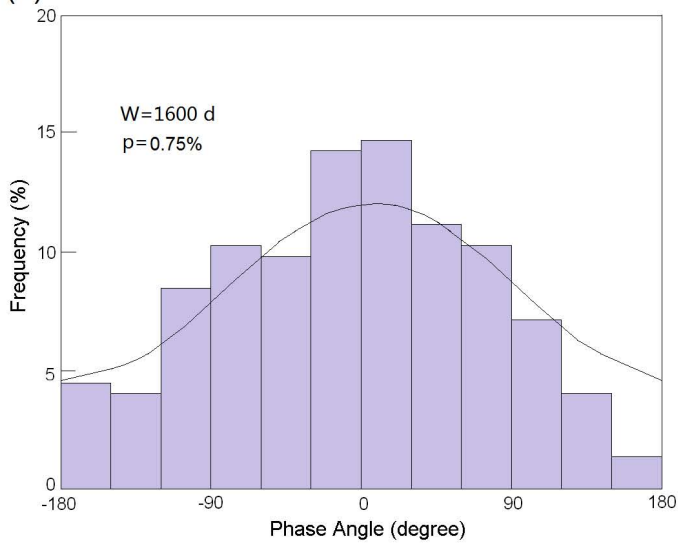

(d)

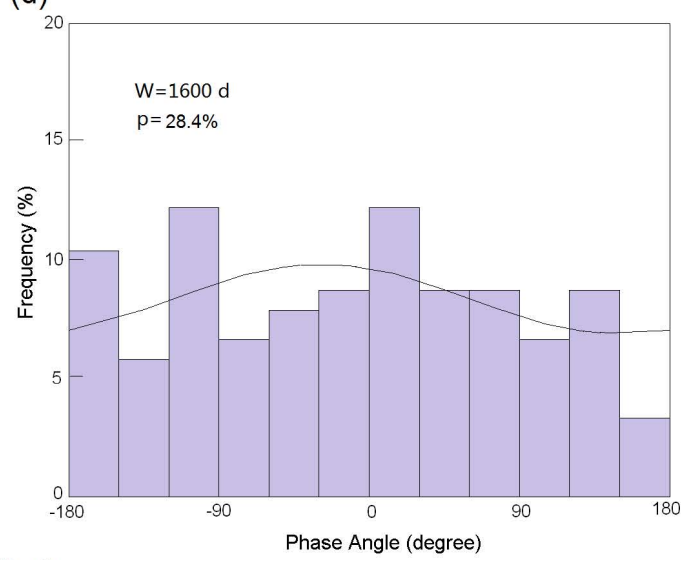

Fig. 8. (a) Variation of $p$ value with time in the Luquan region. The time window length, indicated by a horizontal line, is 1200 days, and the step length is 200 days. (b) Phase angle frequency change for events during the period of 1600 days before the Luquan $M_{\mathrm{S}}=6.3$ earthquake. The fine solid curve signifies a sinusoidal function which corresponds to the least square fit to the change. The fitting time window is a full period of sinusoidal function. (c) Variation of $p$ value with time in the Yaoan region. The time window length, indicated by a horizontal line, is 1200 days, and the step length is 200 days. (d) Phase angle frequency change for events during the period of 1600 days before the Yaoan $M_{\mathrm{S}}=6.5$ earthquake. The fine solid curve signifies a sinusoidal function which corresponds to the least square fit to the change. The fitting time window is a full period of sinusoidal function.

in these two regions shows that the dominant azimuth of the principal stress axes ranges from $54^{\circ}$ to $85^{\circ}$, which are close to the azimuths of the regional tectonic stress of these two regions, also indicating that the focal mechanism is related to the regional tectonic stress.

As for the third group of cases, we produced the statistics on the types of focal mechanisms (total 103 earthquakes) according to the published data (Wu et al., 2004) and existing databases provided by the Research Center for Earthquake Prediction, EAJPC. The statistical results show that the susceptible types (normal, reverse, oblique) in the Luquan region and the Yaoan region are 54.4 and $55.7 \%$ of the above data, respectively, signifying that the type of focal mechanism is unlikely to be responsible for the above difference.

In addition, the depth of seismic events is not responsible for above differences because the earthquakes that occurred in the six regions all belong to the shallow earthquakes.

\section{Discussion and conclusion}

In this study, we investigated the connection between the tidal variations and earthquake occurrence in the Liyang, Wunansha, Cangshan, Wenan, Luquan and Yaoan regions of China. Most of these regions show a higher connection with tidal triggering in several years preceding large or destructive earthquakes compared to other times, indicating that the tidal triggering may inherently relate to the nucleation of these destructive earthquakes during this time. In addition, the analysis results indicate that the Liyang, Cangshan and Luquan regions, with stronger heterogeneity, show statistically significant effects of tidal triggering preceding the large or destructive earthquakes, while the Wunansha, Wenan and Yaoan regions, with relatively weak heterogeneity, statistically show insignificant effects of it. The examination of focal mechanism and depth differences show that the types of focal mechanism and the depth of seismic events are unlikely to be 
responsible for the above differences. These results signify that the precursory pattern of tidal triggering of earthquakes in these six regions is possibly related to the heterogeneities of the crustal rocks. In fact, the heterogeneities of the rock can strongly influence the non-linear behavior of rock deformation (Jiao et al., 2003); for example, under a condition of high stress, a high degree of heterogeneity can increase the non-linear behavior of rock deformation, while a low degree of heterogeneity can decrease this behavior. This non-linear behavior of rock deformation is the prerequisite for a critical stress state (Yin and Yin, 1991) in which the tidal stress could trigger an earthquake. Therefore, it is likely easier for tidal stress to trigger an earthquake in rocks with stronger heterogeneity.

The above results suggest that when people try to find the potential earthquake hazardous areas or make middle-longterm earthquake forecasting by means of precursory pattern of the tidal triggering, the crustal heterogeneity in these areas has to be taken into consideration for the purpose of increasing the prediction efficiency. If they do not consider the influence of crustal heterogeneity on the tidal triggering of earthquakes, the prediction efficiency might greatly decrease.

Acknowledgements. We thank S. S. Dong for helpful conversations. This work is supported by the United Fund of Earthquake Science of China (A08024).

Edited by: B. D. Malamud

Reviewed by: D. Bohnenstiehl and two anonymous referees

\section{References}

Aki, K.: Scattering and attenuation of shear waves in the lithosphere, J. Geophys. Res, 85, 6496-6504, 1980.

Akinci, A. and Eyidoan, H.: Scattering and anelastic attenuation of seismic energy in the vicinity of north Anatolian fault zone, Eastern Turkey, Phys. Earth Planet. In., 122, 229-239, 2000.

Bianco, F., Del Pezzo, E., Castellano, M., Ibanez, J., and Di Luccio, F.: Separation of intrinsic and scattering seismic attenuation in the Southern Apennine zone, Italy, Geophys. J. Int., 150, 10-22, 2002.

Cochran, E. S., Vidale, J. E., and Tanaka, S.: Earth tides can trigger shallow thrust fault earthquakes, Science, 306, 1164-1166, 2004.

Dziewonski, A. M. and Anderson, D. L.: Preliminary reference Earth model, Phys. Earth Planet. In., 25, 297-356, 1981.

Fehler, M., Hoshiba, M., Sato, H., and Obara, K.: Separation of scattering and intrinsic attenuation for the Kanto-Tokai region, Japan, using measurements of S-wave energy versus hypocentral distance, Geophys. J. Int., 108, 787-800, 1992.

Fu, S.- F. and Liu, B.-C.: A course in seismology, Seismological Press-Beijing, 1991 (in Chinese).

Gardner, J. K. and Knopoff, L.: Is the sequence of earthquakes in southern California, with aftershocks removed, Poissonian?, B. Seismol. Soc. Am., 64, 1363-1367, 1974.

Heaton, T. H.: Tidal triggering of earthquakes, Geophys. J. R. Astr. S., 43, 307-326, 1975.
Heaton, T. H.: Tidal triggering of earthquakes, B. Seismol. Soc. Am., 72, 2181-2200, 1982.

Hoshiba, M., Sato, H., and Fehler, M. C.: Numerical basis of the separation of scattering and intrinsic absorption from full seismogram envelope - A Monte-Carlo simulation of multiple isotropic scattering, Papers Meteor. \& Geophys, 42, 65-91, 1991.

Huang, Q.: A method of evaluating reliability of earthquake precursors, Chinese J. Geophys., 48, 637-642, 2005.

Huang, Q.: Search for reliable precursors: A case study of the seismic quiescence of the 2000 western Tottori prefecture earthquake, J. Geophys. Res., 111, B04301, doi:10.1029/2005JB003982, 2006.

Huang, Q.: Seismicity changes prior to the $M_{\mathrm{S}} 8.0$ Wenchuan earthquake in Sichuan, China, Geophys. Res. Lett., 35, L23308, doi:23310.21029/22008GL036270, 2008.

Huang, Q. and Liu, T.: Earthquakes and tide response of geoelectric potential field at the Niijima station, Chinese J. Geophys.-Ch, 49, 1745-1754, 2006.

Jiao, M. R., Tang, C. A., Zhang, G. M., Shi, Y. L., and Hou, W. K.: Numerical test of influence of mesoscopic heterogeneity on macroscopic behavior of rock failure and seismic sequence types, Chinese J. Geophys.-Ch, 46, 659-666, 2003.

Kanamori, H. and Anderson, D. L.: Theoretical basis of some empirical relations in seismology, B. Seismol. Soc. Am., 65, 10731095, 1975.

Kasahara, J.: Tides, earthquakes and volcanoes, Science, 297, 348349, 2002.

Lan, C. X., Xing, C. Q., Miao, C. L., Yue, X. Y., Guo, X., and Yuan, X. M.: The focal mechanism solutions and their characteristics for moderate and small earthquakes in Capital Area in recent years, North China Earthquake Sciences, 23, 21-25, 2005 (in Chinese with English abstract).

Liu, H. G., Miao, F. J., Xu, G., Sun, Q. W., and Shan, C. L.: The application of the $\mathrm{P}$ axis-trend of earthquake mechanisms to earthquake prediction, Journal of Disaster Prevention and Mitigation Engineering, 24, 307-312, 2004a (in Chinese with English abstract).

Liu, J. Z., Li, S. Z., Zhou, L. H., Gao, Z. P., and Guo, X. Y.: Mesozoic tectonics and basin distribution in the Eastern North China Plate, Marine Geology \& Quaternary Geology, 24, 45-54, 2004b (in Chinese with English abstract).

Li, Q. and $\mathrm{Xu}, \mathrm{G} .-\mathrm{M} .:$ Tidal triggering of earthquakes in Longmen Shan region: the relation to the fold belt and basin structures, Earth Planets Space, 64, 771-776, 2012.

Luo, L.-G., Han, W.-B., and Liu, Y.-W. (Eds.): Research on the method and efficiency of medium-short term prediction for strong earthquakes. Seismological Press, Beijing, 2002 (in Chinese).

Métivier, L., Viron, O. D., Conrad, C. P., Renault, S., Diament, M., and Patau, G.: Evidence of earthquake triggering by the solid earth tides, Earth Planet. Sc. Lett., 278, 370-375, 2009.

Matsumoto, K., Takanezawa, T., and Ooe, M.: Ocean tide models developed by assimilating TOPEX/POSEIDON altimeter data into hydrodynamical model: A global model and a regional model around Japan, J. Oceanogr., 56, 567-581, 2000.

Mohler, A. S.: Earthquake/earth tide correlation and other features of the Susanville, California, earthquake sequence of June-July 1976, B. Seismol. Soc. Am., 70, 1583-1593, 1980. 
Qian, X.-D., Qin, J.-Z., and Liu, L.-F.: Study on recent tectonic stress field in Yunnan region, Seismology and Geology, 33, 91106, 2011 (in Chinese with English abstract).

Reasenberg, P.: Second-order moment of central California seismicity, 1969-1982, J. Geophys. Res, 90, 5479-5495, 1985.

Schuster, A.: On lunar and solar periodicities of earthquakes, P. R. Soc. London, 455-465, 1897.

Shan, C.-L., Li, Y.-H., Li, X., Yan, Q., Zhang, Z.-H., and Li, Z.J.: Characteristics of the focal mechanism for parts of moderate and small earthquakes in Shandong and its neighboring region, North China Earthquake Sciences, 25, 27-30, 2007 (in Chinese with English abstract)

Shen, J., Wang, Y.-P., Song, F.-M., Yu, W.-X., Gao, Z.-Q., Hou, X.Y., Shen, X.-H., and Li, Z.-X.: The evolution stages of the late Cenozoic tectonic basins in the central part of the Xiaojiang fault zone, Journal of Seismological Research, 21, 58-64, 1998 (in Chinese with English abstract).

Stroup, D. F., Bohnenstiehl, D. R., Tolstoy, M., Waldhauser, F., and Weekly, R. T.: Pulse of the seafloor: Tidal triggering of microearthquakes at $9^{\circ} 50^{\prime} \mathrm{N}$ East Pacific Rise, Geophys. Res. Lett, 34, L15301, doi:10.1029/2007GL030088, 2007.

Tanaka, S.: Tidal Triggering of Earthquakes Precursory to the 2004 $M_{\mathrm{W}}=9.0$ Off Sumatra Earthquake, 9-13, in: 4th Int. Workshop on Statistical Seismology, Graduate University for Advanced Studies, Kanagawa, Japan, 2006.

Tanaka, S.: Tidal triggering of earthquakes precursory to the recent Sumatra megathrust earthquakes of 26 December $2004\left(M_{\mathrm{W}} 9.0\right)$, 28 March $2005\left(M_{\mathrm{W}} 8.6\right)$, and 12 September $2007\left(M_{\mathrm{W}} 8.5\right)$, Geophys. Res. Lett., 37, L02301, doi:10.1029/2009GL041581, 2010.

Tanaka, S., Ohtake, M., and Sato, H.: Evidence for tidal triggering of earthquakes as revealed from statistical analysis of global data, J. Geophys. Res, 107, 2211, doi:10.1029/2001JB001577, 2002.

Tanaka, S., Ohtake, M., and Sato, H.: Tidal triggering of earthquakes in Japan related to the regional tectonic stress, Earth Planets Space, 56, 511-516, 2004.

Thomas, A. M., Nadeau, R. M., and Burgmann, R.: Tremor-tide correlations and near-lithostatic pore pressure on the deep San Andreas fault, Nature, 462, 1048-1051, 2009.
Tsuruoka, H., Ohtake, M., and Sato, H.: Statistical test of the tidal triggering of earthquakes: contribution of the ocean tide loading effect, Geophys. J. Int., 122, 183-194, 1995.

Ugalde, A., Tripathi, J., Hoshiba, M., and Rastogi, B.: Intrinsic and scattering attenuation in western India from aftershocks of the 26 January, 2001 Kachchh earthquake, Tectonophysics, 429, 111123, 2007.

Vidale, J. E., Agnew, D. C., Johnston, M. J. S., and Oppenheimer, D. H.: Absence of earthquake correlation with earth tides: An indication of high preseismic fault stress rate, J. Geophys. Res., 103, 24567-24572, 1998.

Wiemer, S. and Wyss, M.: Minimum Magnitude of Completeness in Earthquake Catalogs: Examples from Alaska, the Western United States, and Japan, B. Seismol. Soc. Am., 90, 859-869, 2000.

Wilcock, W. S. D.: Tidal triggering of microearthquakes on the Juan de Fuca Ridge, Geophys. Res. Lett, 28, 3999-4002, 2001.

Wu, J.-P., Ming, Y.-H., and Wang, C.-Y.: Source mechanism of small-to-moderate earthquakes and tectonic stress field in Yunnan Province, Acta Seismologica Sinica, 26, 457-465, 2004.

Wu, R. S. and Aki, K.: Multiple scattering and energy transfer of seismic waves - separation of scattering effect from intrinsic attenuation II. Application of the theory to Hindu Kush region, Pure Appl. Geophys., 128, 49-80, 1988.

Xie, F. R., Cui, X. F., Zhao, J. T., Chen, Q. C., and Li, H.: Regional division of the recent tectonic stress field in China and adjacent areas, Chinese J. Geophys.-Ch., 47, 654-662, 2004.

Ye, Z., Ma, L., Liang, X., Wu, G. Y., and Xu, K. D.: The independent Lower Yangtze Block and Mesozoic reformed residual basins, Chinese Journal of Geology, 41, 81-101, 2006 (in Chinese with English abstract).

Yin, X. C. and Yin, C.: The precursor of instability for nonlinear systems and its application to earthquake prediction, Sci. China Ser. B, 34, 977-986, 1991.

Young, D. and Zurn, W.: Tidal triggering of earthquakes in the Swabian Jura, J. Geophys., 45, 171-182, 1979.

Zeng, Y.: Compact solutions for multiple scattered wave energy in time domain, B. Seismol. Soc. Am., 81, 1022-1029, 1991. 